\title{
Pattern of physical disability in Kurigram District, Bangladesh
}

\begin{abstract}
A person with a physical disability is constrained by his physical ability to perform an activity independently such as walking, bathing, toileting etc. The purpose of the study was to assess the pattern of physical disability and causes with physical disability, to observe the socio-demographic status among the patient at the Integrated Disability Service Center (IDSC). A descriptive Cross-sectional study was conducted and a pretested semi-structured questionnaire were used for data collection. Purposive sampling technique was adopted for selecting a total 117 sample population. And physical disable patients comprised69 males $(59 \%), 48$ females $(41 \%)$ including mean age \pm 46 years and standard deviation (SD) 22.53. A variety of disability pattern observed in pain $15.4 \%$, paralysis $23.9 \%$, absent limb $10.3 \%$, short limb $7.7 \%$, contracture $35.9 \%$, and Inco-ordination $6.8 \%$.Causes of physical disability, majority was unknown $27.4 \%, 15.4 \%$ congenital, $23.1 \%$ chronic Illness, $18.8 \%$ accident \& Injury. Duration of physical disability was below 2 years (58.1\%), 2-4 years $(18.8 \%),>10 y e a r s(6 \%)$. Disability developed among the respondents within the two years.
\end{abstract}

Volume 10 Issue I - 2018

\author{
Arif Hossain,' Jobair Khan, ${ }^{2}$ Golam Mostafa' \\ 'Protibondhi sheba o sahajjy kendra, Bangladesh \\ ${ }^{2}$ Apollo Hospitals Dhaka, Bangladesh
}

Correspondence: Jobair Khan, MD, Apollo Hospitals, Dhaka, Bangladesh, Tel 880-1912048846,

Emailkhan_pavel08@yahoo.com

Received: July 21, 2017| Published: January 10, 2018

Keywords: Disability, Physical disability, Pain, Paralysis, Short limb, Absence limb, Incoordination, Integrated disability service center, IDSC

Abbreviations: DMCH, Dhaka Medical College Hospital; IDSC, Integrated Disability Service Center; NCDs, NonCommunicable Disease; MSK, Musculoskeletal; WHO, World Health Organization

\section{Introduction}

\section{Background}

Apart from infection and malnutrition, an excess burden of cerebrovascular disease and stroke at an early age denoted a higher risk of mortality and morbidity in Bangladesh. As neurologic disorders were quite common among all medical admissions in $\mathrm{DMCH}$ and there were lack of facilities elsewhere in the country. ${ }^{1}$

Birth defects emerged as the major childhood health problem. The disease burden results in neonatal deaths and nearly 3.2 million birth defect-related disabilities every year. ${ }^{2}$ Musculoskeletal pain was one of the most common reasons for morbidity and consultation to general practice. ${ }^{3}$ Diabetes occurred a multi-system disorder affecting $3-7 \%$ of the adult population in different geographical areas. Diabetic patients presented with various MSK disorders like adhesive capsulitis of shoulder joint, trigger finger, catching and snapping of the fingers and complications involving joints e.g. Charcot's arthropathy were frequent in diabetic patients. ${ }^{4}$

In 2005 chronic Non communicable diseases (NCDs) accounted for $60 \%$ of all global mortality and $47 \%$ of global morbidity; projection was that by 2020 , these figures will be rising to $73 \%$ and $60 \%$ respectively. Currently, $80 \%$ of chronic diseases were now occurring in developing economies. ${ }^{5} \mathrm{NCDs}$ started causing major problems in industrialized countries among them heart diseases, cancer, diabetes, chronic pulmonary and mental the leading causes of disease burden. A projection was that by 2020, NCDs would be accounting for 80 percent of the global burden of disease, causing seven out of every ten deaths in developing countries, compared with less than half today. ${ }^{6}$ Sometimes chronic diseases considered communicable at the risk factor level. Modern dietary and physical activity patterns were risk behaviors that travel across countries and transferable from one population to another like an infectious disease, affecting disease pattern globally. ${ }^{7}$

The extent of orthopedic problems in children varied in different regions due to racial factors, environmental factors or geographical peculiarity of a terrain and it was imperative to know the extent of problem. ${ }^{8}$

\section{Materials and methods}

This descriptive Cross-sectional study conducted in IDSC, Kurigram, Bangladesh, over the four months from September to December 2016. The study sample were selected from the registered population when the people attending treatment session center. Physical disability measured by physical examination (muscle power by Oxford grading and range of motion by Goniometer) as well as clinical examination (X-ray).Purposive Sampling technique was adopted for the study. A pretested semi-structured questionnaire was used in order to collect data through face-to-face interview. For the pretest ten samples were taken. All interviewed questionnaires were checked and rechecked for its completeness, accuracy and consistency to exclude missing or inconsistent data. Later, analyzed by using the software SPSS-16. The analyzed data were presented in tables, graphs, charts and bars, descriptive statistics were used for the interpretation of the findings.

\section{Result and discussion}

\section{Results}

After completing the data analysis the following results were found from the study: Among the respondents $14.5 \%$ were in the age group below 15 years, $6.8 \%$ in $16-30$ years, $21.4 \%$ in $31-45$ years, $30.8 \%$ in $46-60$ years, 19.7 in $61-75 y$ years and $6.8 \%$ were more than above 75 years. Mean age of the respondents were $46 \pm 22.53$. Among the 117 physically disable patients; it was found that $59 \%$ male and $41 \%$ females (Table 1 ). 
Table I Distribution of the respondents by age and sex

\begin{tabular}{lll}
\hline Age in (Years) & Number & Percentage \\
\hline Below I5 & 17 & 14.5 \\
$16-30$ & 8 & 6.8 \\
$31-45$ & 25 & 21.4 \\
$46-60$ & 36 & 30.8 \\
$61-75$ & 23 & 19.7 \\
Above 75 & 8 & 6.8 \\
Total & 117 & 100 \\
Sex & Number & Percentage \\
Male & 69 & 59.0 \\
Female & 48 & 41.0 \\
Total & 117 & 100 \\
\hline
\end{tabular}

Distribution of the respondents by occupational status depicted; Government service 6.8\%, Non-government organization (NGO) service $13.7 \%$, Business $18.8 \%$, Daily labor $12.8 \%$, Retired $8.5 \%$ and others $39.4 \%$ (Figure 1).

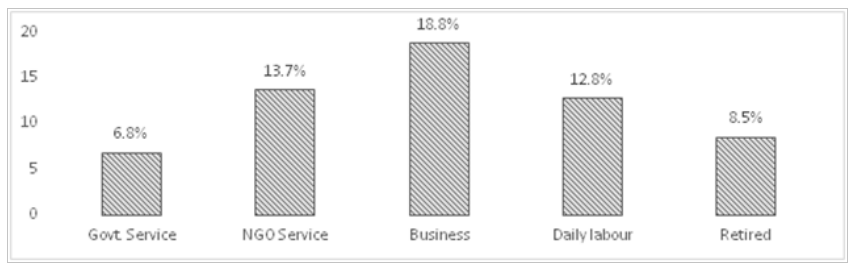

Figure I Distribution of the respondents by occupational status.

Distribution the pattern of physical disability, among the respondents; pain were $15.4 \%$ (18), paralysis $23.9 \%$ (28), absent limb $10.3 \%$ (12), short limb 7.7\% (9), contracture $35.9 \%$ (42), and in coordination $6.8 \%$ (8) (Table 2).

Table 2 Distribution of the respondents by pattern of physical disability

\begin{tabular}{lll}
\hline Types of physical disability & Number & Percentage \\
\hline Pain & 18 & 15.4 \\
Paralysis & 28 & 23.9 \\
Absent limb & 12 & 10.3 \\
Short limb & 9 & 7.7 \\
Contracture/Deformity & 42 & 35.9 \\
Inco-ordination & 8 & 6.8 \\
Total & 117 & 100 \\
\hline
\end{tabular}

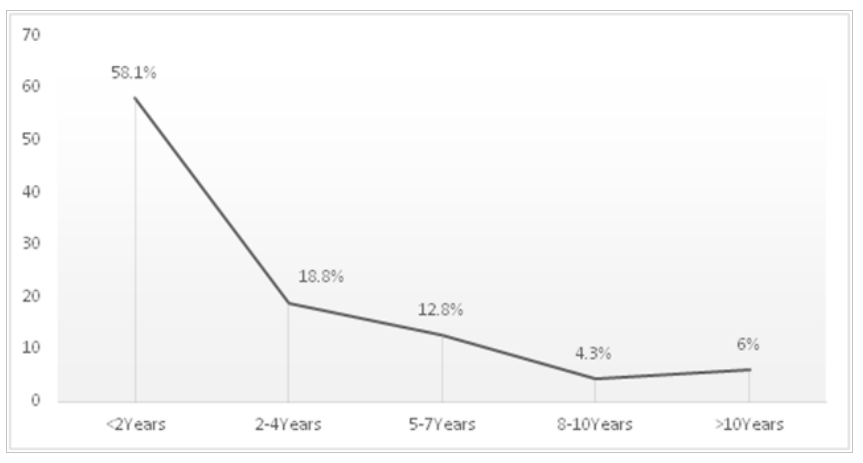

Figure 2 Distribution of the respondents by Duration of disability.

Duration of physical disability was distributed (Figure 2), among the respondents below 2 years $(58.1 \%), 2-4$ years $(18.8 \%), 5-7$ years (12.8\%), 8 -10 years $(4.3 \%)$ and above 10 years $(6 \%)$.

Table 3 described that the causes of physical disability, there were $27.4 \%$ (32) unknown, $15.4 \%$ (18) congenital, 23.1\% (27) chronic Illness, $18.8 \%$ (22) accident \& injury, $14.5 \%$ (17) others.
Table 3 Distribution of the respondents by causes of physical disability

\begin{tabular}{lll}
\hline Causes of Physical Disability & Number & Percentage \\
\hline Unknown & 32 & 27.4 \\
Congenital & 18 & 15.4 \\
Chronic Illness & 27 & 23.1 \\
Accident \& Injury & 22 & 18.8 \\
Others & 17 & 14.5 \\
Total & 117 & 100 \\
\hline
\end{tabular}

Occupational hazard of the respondents were explaining, among the respondents $68.4 \%(80)$ were and remaining $31.6 \%$ (37) were not suffering from occupational hazard (Figure 3).

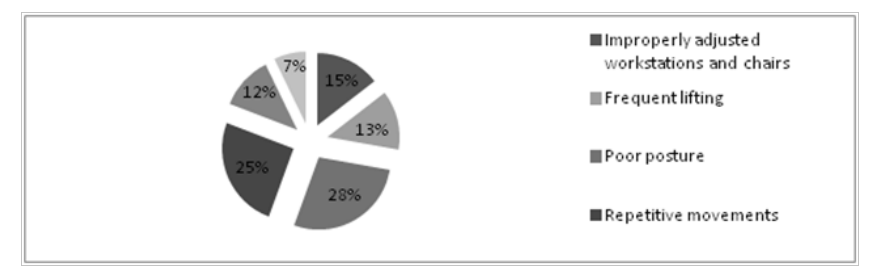

Figure 3 Distribution of the respondents by types of occupational hazards.

Types occupational hazard of the respondents were showing, improperly adjusted workstations and chairs $15 \%$, frequent lifting $13 \%$, Poor posture $28 \%$, repetitive movements $25 \%$, and having to use too much force $12 \%$ (Table 4 ).

Table 4 Distribution of the respondents by occupational hazards

\begin{tabular}{lll}
\hline Occupational hazards & Number & Percentage \\
\hline Yes & 80 & 68.4 \\
No & 37 & 31.6 \\
Total & 117 & 100 \\
\hline
\end{tabular}

\section{Discussion}

Meaning of physical disability was introduced person disabled through pain, paralysis, loss of limb and in coordination. Among the 117 physically disabled patients, male and female participants founded $59 \%$ and $41 \%$ respectively. Age range categorized into six group, most of the participants $30.8 \%(n=36)$ from $46-60$ years were twice as bellow 15 years as in $14.5 \%(n=17)$. Participants were four times $(21.4 \%, n=25)$ higher in the age between $31-45$ years compare to the equal number $(6.8 \%, n=8)$ of participants were the age group $16-30$ and above 75 years age $(6.8 \%)$.

Counting five sorts of occupational status, greater percentage (18.8\%) of participants engaging in business, Govt. service $(6.8 \%)$ were $2.7 \%$ lower from retired $(8.5 \%)$ and status of daily labor $(12.8 \%)$ nearer to NGO service holder (13.7\%).

One-third $(35.9 \%, \mathrm{n}=42))$ discovered contracture or deformity, another one-third were combinely paralysis and pain $(23.9 \%, n=28$ and $15.4 \%, \mathrm{n}=18)$, absent limb $10.3 \%(\mathrm{n}=12)$ and short limb $7.7 \%$ $(\mathrm{n}=9)$.

Study noted that disability developed faster within 2 years (58.1\%), interestingly lowering trend $6 \%$ and $4.3 \%$ were observed with the increase of duration $>10$ years and 8-10 years respectively. Unknown reason of the higher percentage of physical disability were seen about $27.4 \%(\mathrm{n}=32)$ and respondent failed to give proper information, confirmed by clinical examination $23.1 \%(\mathrm{n}=27)$ were responsible for the chronic illness, $18.8 \%$ accident and injury, $15.4 \%$ congenital and least $14.5 \%$ among others.

Occupational hazard made sufferer $68.4 \%(n=80)$ respondents in contrast for $31.6 \%(n=37)$ were not responsible. Hazards from the 
types of occupational reasons, percentage of the adaptation of poor posture was highest $28 \%$, repetitive movement $25 \%$, agronomical reason- improper adjustment in workstation and chair $15 \%$, frequent lifting $13 \%$ and physical force used $12 \%$.

However, this study had some limitations. Sample size was a major issue, next related to the insufficient funding and study conducted in a selected IDSC; therefore results may devoid of reflection of the total population in the country. As the persons with disabilities are socially neglected, physically disordered or unsound, they showed reluctance to cooperate in many cases.

\section{Conclusion}

Study addresses the real scenario of higher adaptation of poor posture, highest in occupational hazards and mostly deformity and paralysis pattern of physical disability where introduced. Surprisingly, suffering from the disability developed within the two years. Therefore, proper diagnosis and appropriate treatment, awareness, education should be carried out in time to reduce physical disability. Reduce the social stigma, encourage for social participation and occupational facilities can reduce the burden of disability life.

\section{Acknowledgements}

None.

\section{Conflicts of interest}

None.

\section{References}

1. Chowdhury RN, Hasan ATMH, Rahman Y, et al. Pattern of neurological disease seen among patients admitted in tertiary care hospital. BMC Res Notes. 2014;7:202

2. Banu T, Chowdhury T K, Das S K, et al. Birth Defects: A Hospital Based Study in Chittagong, Bangladesh. Chattagrammaa-o- shishu hospital medical college journal. 2014;13: 3.

3. Koiri R, HaqueMd M, Kamrujjaman M, et al. Pattern of Musculoskeletal Disorder and Associated Factors among Garo Ethnic Community Orthop Rheumatol Open Access J. 2015;1(1).

4. Khan Md S Z, Shakoor MA, Moyeenuzzaman Md, et al. pattern of musculoskeletal disorders among diabetic patients attending a tertiary care hospital in Dhaka. Ibrahim Med Coll J. 2008;2(2):65-66.

5. Ogah OS, Madukwe OO, Onyeonoro UU, et al. Cardiovascular risk factors and non-communicable diseases in Abia state, Nigeria: report of a community-based survey. International Journal of Medicine and Biomedical Research. 2013;2(1).

6. Boutayeb A and Boutayeb S. The burden of non communicable diseases in developing countries. International Journal for Equity in Health. $2005 ; 4(1): 2$

7. Sharma M, Kumar D. Health Care Utilization Pattern for Communicable and Non-Communicable Diseases In A Tertiary Care Health Facility In Chandigarh, India. The Internet Journal of Health. 2007;7(2).

8. Agarwal S.AProspective Hospital Based Study of Childhood Orthopaedic Problems - A Case Series. J Clin Diagn Res. 2014;8(12):LC01-LC03. 